\title{
Is Entrepreneurship for You? Effects of Storytelling on Entrepreneurial Intention
}

\author{
Amel Hamrouni Dakoumi ${ }^{1,2}$ \& Yosra Abdelwahed ${ }^{1,2}$ \\ ${ }^{1}$ Higher Institute of Management, University of Sousse, Tunisia \\ ${ }^{2}$ Member of the Research Laboratory ERMA, Faculty of Economic Sciences and Management of Tunis, Tunisia \\ Correspondence: Amel Hamrouni Dakoumi, Member of the Research Laboratory ERMA, Higher Institute of \\ Management, University of Sousse, Rue Abdelaziz El Behi, 4000, Sousse, Tunisia. Tel: 216-333-2976. E-mail: \\ amelhamrouni@yahoo.fr
}

Received: May 14, 2014

Accepted: June 17, 2014

Online Published: August 22, 2014

doi:10.5539/ijbm.v9n9p176

URL: http://dx.doi.org/10.5539/ijbm.v9n9p176

\begin{abstract}
Storytelling is an important means of communication for young people which allows them to be future leaders and also provides them a vision and new ideas. The purpose of this study is to determine how storytelling can influence the individual's intention, based on Ajzen's theory of planned behavior. This research has been based on a sample of engineering students. A total of 251 completed questionnaires have been used for the data analysis. The research model has been tested with structural equation modeling techniques. The results have come up with the idea that storytelling can act as a trigger and informational tool in the field of entrepreneurship, thus suggesting that story might be the departure point for new business creation. The authors concerned think that the best way to make them aware of "the entrepreneurial intention" at the students' level is mostly through a story.
\end{abstract}

Keywords: entrepreneurial intention, theory of planned behavior, storytelling, structural equations

\section{Introduction}

Starting up a new firm is very much an individual decision, which is what the entrepreneurial intentions is central in the investigation of entrepreneurships (Zampetakis \& Moustakis, 2006; Laviolette et al, 2010). "Entrepreneurial intentions" is one's willingness in understanding entrepreneurial activity, or in other words become self employed (Krueger \& Brazeal, 1994; Krueger, Reilly, \& Carsrud, 2000). On the one hand, intentions have raised a growing interest among researchers claiming that they play a significant role in the new business creation. Among other researchers, Brand (1984) (Note 1) has identified the importance of intentions in understanding this personal decision. As far these latter, Intentions are combined between both the will to act and the belief that one will act should be the immediate cause of act itself (Brand, 1984) (Note 1). In addition, the motivational factors that influence a behavior are supposed to capture the intentions (Ajzen, 1991). On the other hand, Zampetakis \& Moustakis (2006) point out that intentions are considered as an important antecedent of planned behavior. Hence, they say that "it seems obvious that much of what we consider entrepreneurial activity is intentionally planned behavior". Therefore, according to (Zampetakis \& Moustakis, 2006), it is essential to study the factors that can influence an individual's intention towards new business establishment, particularly among the youth, in order to encourage entrepreneurship.

As shown by (Snowden, 1999), Storytelling is described as an old skill in a new context (Snowden, 1999). Accordingly, the new context is the new field of knowledge management that emerged in reply to the growing awareness that intellectual capital is the main resource of organizations and of also the society. Regarding the old skill, it refers to the human capacity to tell stories. The concept of storytelling has been emerged and has been used more and more often in the social sciences, over the last twenty years (Fallery \& Marti, 2005).Accordingly, Stories occupy a key place in the social sciences, because they represent a preferred means of giving meaning to a situation and to package information into an order. Moreover, (Sole \& Wilson, 2002) claim that, stories can spark social change, by the way, that storytelling is tacitly recognized in various social science fields as a way of communication used to convey powerful vision of leadership and ideas.

According to Johansson (2004), entrepreneurship research has benefited from the narrative studies. In fact, it has 
been proposed that the narrative approach can make a beneficial involvement to the pursuit of entrepreneurship by introducing a better conceptual belief, epistemological and methodological reflection (Steyaert and Bouwen, 1997) (Note 2). Several studies have clearly demonstrated the critical role that the storytelling plays in entrepreneurship (Lounsbury \& Glynn, 2001; Johansson, 2004). The influence of storytelling in enhancing resource acquisition, venture opportunities, building the entrepreneurial identities, entrepreneurial learning and (Re) conceptualizing entrepreneurship have been identified among the academic literature for a long time. Still, we know little about the impact of storytelling on entrepreneurial intentions. In fact, few of the academic literature have tried to examine the entrepreneur's impact on entrepreneurial intentions (Laviolette et al., 2010). The current research starts with a review of the relevant literature which presents the principal explanatory theories of the concept of entrepreneurial intentions and storytelling, followed by a presentation of the research methodology. Analysis and results are discussed. Finally, limitations and directions for future research are provided.

\subsection{Theoretical Framework}

\subsubsection{The Theory of Planned Behavior (Ajzen, 1991)}

As described by Krueger \& Carsrud (1993), Ajzen's intentions-centered theory of planned behavior is parsimonious, well established in theory, and predicts a strong broad range of planned behavior. Accordingly, these cognitive models are consistently robust and replicable in predicting behavior and intentions, including success in studies of career-related behaviors.

As shown by Ajzen (1991), since that any behavior needs a certain amount of planning, the theory of Planned Behavior can be predicted by the intention to assume that one. The theory of planned behavior postulates three basically independent elements of intention which, the first one is the attitude toward the behavior, the second is subjective norm and the third element of intention is perceived behavioral control (Ajzen, 1991).

$>$ Attitudes: As shown by Ajzen (1991), attitudes refer to the degree of the favorable or unfavorable evaluation or judgment that a person may have towards a behavior. Accordingly, this concept taps perceptions of what the subject finds personally desirable or undesirable about performing the behavior. As a check on construct validity, Ajzen \& Fishbein (1980) (Note 1) hypothesize this attitude which depends on opportunity and beliefs about the likely personal impact of outcomes helping from performing the behavior. In this sense, personal attraction is an important element that affects entrepreneurial intention. As shown by Fayolle et al (2006), attitude are automatically formed when new questions are raised demanding an evaluative answer, new people can draw a relevant information stored in memories. This is explained by the way that each of these beliefs carries evaluative implications.

\section{H1: Attitudes to start a business will have a positive effect on entrepreneurial intentions.}

Subjective Norms: it refers to the perceived social difficulty to achieve or not the behavior (Ajzen, 1991). This construct taps subjects' perceptions of' what the important people in their lives think about performing the behavior (e.g., peer pressure, family expectations, etc.); thus it is driven by normative beliefs (Krueger \& Carsrud, 1993).Ajzen (1991) claims that subjective norms assess the perceived social pressure from family, friends or important others to perform the entrepreneurial behavior. He adds that it refers to the perception that "reference people" would or would not; agree with the decision to become an entrepreneur.

\section{H2: Subjective Norms have a positive effect on entrepreneurial intentions.}

$>$ Perceived Behavioral Control: The third antecedent of intention is the degree of perceived behavioral control which refers to the perceived ease or difficulty of achieving the behavior and it is assumed to reproduce past experience as well as predictable problems (Ajzen, 1991).He adds that perceived behavioral control plays a crucial role in the theory of planned behavior. Ajzen (1991) explains the importance of actual behavioral control by the way that it is self evident. In fact the resources and opportunities offered to a person must state the possibility of behavioral attainment. This variable seems be very important for developing a business process because it gives an idea to predict someone's behavior. Thus, perceived behavioral control plays a great role on entrepreneurial intention.

\section{H3: Perceived behavioral control have a positive effect on entrepreneurial intentions.}

\subsubsection{Storytelling}

According to Kaufman (2003), storytelling is one of the oldest and most powerful communication means. In the same line of view , Denning (2005) adds that storytelling is considered as a phenomenon that is essential for all nations, companies and cultures, and can be considered as the first means of communication between people. 
There are many theorists who consider storytelling synonymous with and from the perspective of narrative inquiry whether is it written down or provided orally (Denning, 2005; Simmons, 2001; Shankar et al, 2001; Heo, 2004). According to Shankar, et al (2001) narratives are stories and stories and storytelling help us to make sense of our lives. Similarly, Simmons (2001) says, "basically, a story is a narrative account of an event or events-true or fictional". He explains the difference between giving an example and telling a story by the adding of emotional content and sensory details in the telling. Additionally, Chestek (2010) affirms that a story weaves detail, character, and events into a whole that is greater than the sum of its parts. Denning, (2005) supports Simmons's view and does not make any distinction between story and narrative .He affirms that they both refer to "an account of events that are causally connected in some way". Heo (2004) considers storytelling synonymous with and from the perspective of narrative inquiry whether is it written down or provided orally. He is fully convinced that narrative is a manner of knowing and understanding allowing the capture of richness and variety of meaning among humanity. He also adds that narrative is a mode of communicating who we are, what we do, how we feel, and why we must follow a certain line of action. Furthermore, he affirms that narrative implies information, ideas, theories, and dreams from the perspectives and in the context of the life of somebody. He adds that Individuals believe, observe, deduce, imagine, interact, and make some decisions according to the narrative basics and structures. Heo (2004) states that Storytelling gives individuals chances to make out other narratives in a social context, and to clarify their own thinking. Barker \& Gower (2010) maintain that the strength of storytelling as a communication method, recognizing all humans as storytellers with the capability to send and receive messages that create a value-laden reality, establishes a common ground between all participants and provides a quicker method of establishing a social relationship. The story is also regarded by Denning (2005) as independent of the media through which it is transmitted. He declares that a story can be transmitted by words, by pictures, by video, or by mime. Further, he argues that while recognizing the suitability of language to communicate narrative, it is possible to study narrative in its nonverbal manifestations without requiring verbal narration.

Vannini (2012) argues that stories are narrative people who tell experiences, events, either personal and collective memories, or aspects of individual biographies. They could be shared verbally, using the written word, or using other ways of communication. He adds that Storytelling is the practice of sharing narratives with self, others, or with researchers. Thus, as a theoretical perspective, storytelling is usually explained as a way that individuals use to make sense in their own lives. Hence, stories and storytelling are considered as a communication way used to run and interpret both collective and individual phenomena as far as making sense of personal and shared experiences.

\section{$>$ Knowledge}

According to Carter (1993), the story is a mode of knowing that captures in a special way the prosperity and the nuances of sense in human affairs. Thus, story, with its multiplicity of meanings, is an appropriate form to express the knowledge resulting from action. A number of scholars, sharing this sight and questing for theoretical and empirical evidence, have proved that stories are the best and powerful way of knowing (Gabriel, 2000; Shank, 1998; Mitchell; Czarniawsk, 1997; Bennet (2001). Shank (1998) affirms that the knowledge is made of experiences and stories, and intelligence is the suitable use of experience and the making and telling of stories. He states that our knowledge of the world is more or less equal to our experiences. Shank adds that, we can understand experiences through those experiences, which are, already in our memory that we understand, so that new ideas are reliant to old ideas. Context gives us the chance to relate received information to those experiences already in our memory, and stories offer that context.Gabriel (2000) argues that storytelling is considered as an art of weaving, of constructing and production of intimate knowledge. It is a delicate process that can easily break down, fading to live up to its promises. Gabriel believes that stories and experience are linked, meaning that stories can turn into experience and experience can change into stories and says that storytelling goes on almost continually.

As knowledge conducts to more and better entrepreneurial opportunities, we suggest that specific knowledge about entrepreneurship learned from a storytelling might improve the participants' opportunity-identification ability and thus would increase their entrepreneurial attitudes and intentions. Thus, there is anticipated to be a positive relationship between the degree of knowledge from storytelling and entrepreneurial intention. In this sense, we aim at corroborating the following hypothesis:

\section{H4: Knowledge from storytelling has a positive effect on entrepreneurial intentions.}

H4a: Knowledge from storytelling has a positive effect on attitude toward the behavior.

H4b: Knowledge from storytelling has a positive effect on social norms. 
.H4c: Knowledge from storytelling has a positive effect on Perceived Behavioral Control.

\section{$>$ Inspiration}

According to Gabriel (2000), storytelling is an art of weaving, of constructing, the product of intimate knowledge. He says that "good stories may entertain, inspire and are not something that can be mass-produced". Simmons (2001) asserts to the ability of story may inspire, influence and persuade, thus, People don't want more information because they are up to their eyeballs in information. She affirms that the faith moves mountains, not the facts. She goes on saying that what is needed is a meaningful story that inspires people to believe in what they believe. When they do this, they will pick up where they left off because they believe. It has become their story and they will retell this story to others as being theirs. Inspiration was generally defined as "the infusion of some idea or purpose into the mind and the awakening or creation of some feeling of impulse" (Oxford English Dictionary; Simpson and Weiner, 1989) (Note 3).As show by V. Souitaris et al (2007), the psychology literature developed a more sophisticated conceptualization of the construct. In a comprehensive review of the literature, Thrash and Elliot (2003) suggested that: inspiration is characterized by: (a) transcendence, (b) evocation, and (c) motivation. Transcendence means that inspiration orients one towards something that is better or more important than one's usual concerns; one sees better possibilities. Evocation means that inspiration is evoked and unwilled; one does not feel directly responsible for becoming inspired. Finally, inspiration involves motivation to express or make manifest which is newly apprehended; given the positive valence of this aim, inspiration is conceptualized as an appetitive motivational state. They add that Inspiration as a mystic influence provides an example for our conceptualization: the individual apprehends something ordinarily beyond his or her capacities (i.e., transcendence), because of the influence made by oneself (i.e., evocation) he or she can be moved to communicate or implement something newly apprehended (i.e., motivation). Hence as regarded by Thrash and Elliot (2004) the value of the construct lies, in part, in its ability to integrate phenomena that are diverse in surface content (e.g., religious, creative, inter-personal), because of a coherent underlying conceptual and psychological core (i.e., transcendence, evocation, motivation). Therefore, this study posits that:

\section{H5: Inspiration from storytelling has a positive effect on entrepreneurial intentions.}

H5a: inspiration from storytelling has a positive effect on attitude toward the behavior.

H5b: inspiration from storytelling has a positive effect on social norms.

H5c: inspiration from storytelling has a positive effect on Perceived Behavioral Control.

\section{$>$ Transportation}

According to Green \& Brock (2000), transportation is a means by which narrative can influence beliefs. They define transportation as "absorption into a story "and state that it involves imagery, affect, and attentional focus. They argue that transportation can make narrative experience which seems more similar to a real experience. Hence, transportation is liable to create strong feelings to the story characters; the experiences or beliefs of those characters can then have an improved influence on the readers' beliefs. They argue that, transportation is considered as a convergent process, whereas elaboration could be seen as a divergent process. Rather than having a single focus (e.g., the narrative), a person engaged in elaboration could be accessed according to his or her own opinions, prior knowledge, or other thoughts and experiences in order to evaluate the message at hand. However, under high transportation, the individual may be temporarily removed from the diagrams and current and previous experiences. Therefore, by the way that transportation is hypothesized to be connected to belief or attitude change we suggest that transportation from storytelling would raise the individual's entrepreneurial attitudes and intentions. Therefore, this study posits that:

\section{H6: Transportation from storytelling has a positive effect on entrepreneurial intentions}

H6a: Transportation from storytelling has a positive effect on attitude toward the behavior.

H6b: Transportation from storytelling has a positive effect on social norms.

H6c: Transportation from storytelling has a positive effect on Perceived Behavioral Control.

\subsubsection{Conceptual Model}

As a result of the literature review which is based on the theory of planned behavior, a conceptual model has been conducted to involve the focus on this study. We confine this study to investigating the impact on the individual's intention to act entrepreneurially of the various components of storytelling (inspiration, knowledge and transportation). The conceptual framework has been developed by using the hypotheses as a starting point in order to offer a visual overview of the relationships that are tested in this study. The conceptual framework shows how the storytelling characteristics influence the entrepreneurial intentions. The entrepreneurial intention 
is drawn from the Theory of planned behavior. Therefore, the applicability of the theory is tested as well on this dataset. Hypothesis 1, 2 and 3 test the relationship between entrepreneurial intention and Attitudes to be self employment, Subjective Norms and Perceived Behavioral Control. The relationship is assumed to be positive. The previous analysis allows a schematic representation of a model of the antecedents of entrepreneurial behavior as depicted in the theory of planned behavior. We contend that storytelling may influence each of the three necessary conditions of entrepreneurial intentions, through: knowledge, inspiration, and transportation.

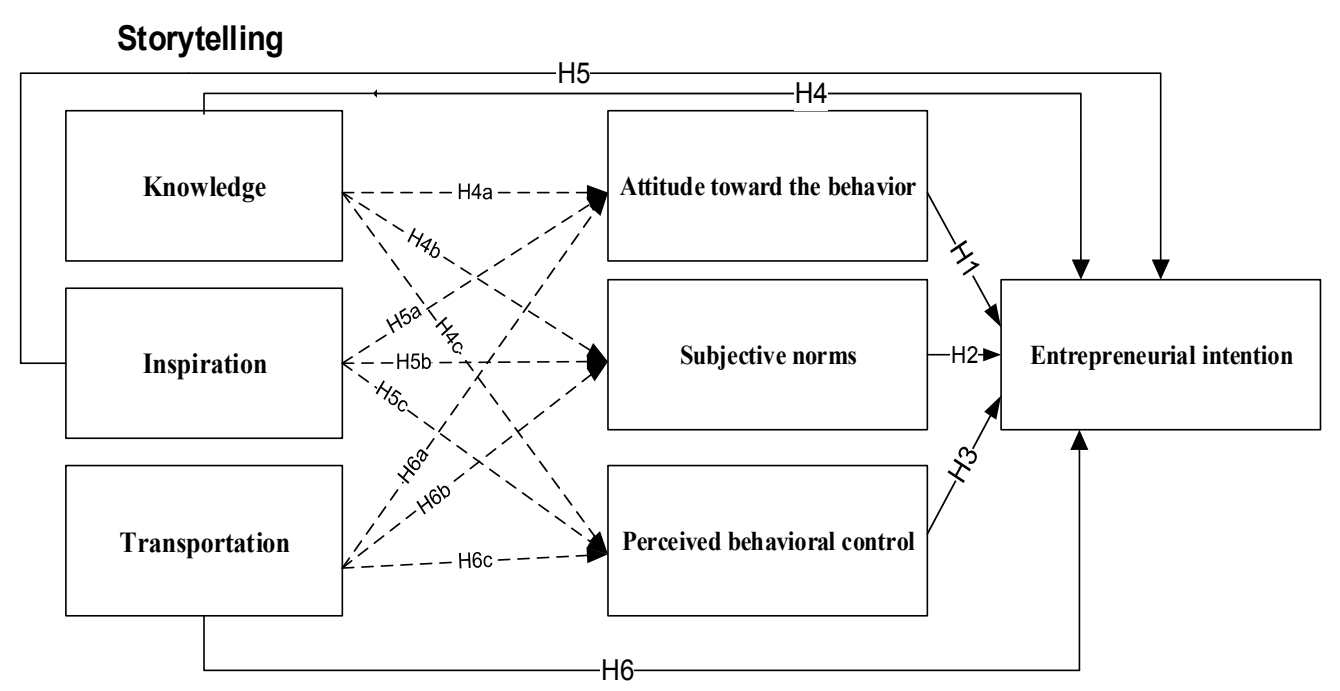

Figure 1. Conceptual model of the effect of storytelling on entrepreneurial intentions

\section{Methodology}

\subsection{Sample}

The sample consists of 300 students from engineering universities in Tunisia. These individuals may be considered potential future entrepreneurs, since they are approaching a career decision point at which they might either enter into employment or seek self-employment.

\subsection{Story Development}

The students were exposed to an entrepreneurial story of Tunisian engineer entrepreneur. The story is presented in a chronological order, and answers the questions related to who, what, why, where, when and how, as Shankar et al (2001) suggest a story should. The story further introduced the people who through their personalities have contributed to what the firm is today. The narrative source was the podcasts of the program of "success story" presented by the radio station Express fm. The show invited every Saturday an entrepreneur and he/she tells his/here story about entrepreneurship. After the exposure to the story, participants were asked to fill in a questionnaire in order to analyze the role of different perceptions of storytelling on the individual's intention to become a self employment.

\subsection{Data Analysis}

Data collected was analyzed using SPSS 18.0 and Structural Equation Model technique through AMOS 18.0. Our statistical analysis was made in three parts; the first one, the descriptive statistical was to define the principal characteristics of the university students. Second, scales were tested for reliability and third for validity. Finally, the statistical analyses to test the hypotheses were conducted. The test of the hypothesized relationships presented in the conceptual model was undertaken using Structural Equation Modeling (SEM).

\section{Results}

\subsection{Profit of Respondents}

A total of 251 samples were used for the data analysis. Survey samples are well distributed in terms of gender and university. As a first step, we conducted a descriptive analysis of data to identify the main features of the sample .A quick overview shows that $34,7 \%$ of student was from the INSAT University, 45, $4 \%$ from ENIT University and 19, 9\% from ESPRIT University. Participants were 42, $6 \%$ female and 57, $4 \%$ male students. 


\subsection{Reliability and Validity Analysis}

\subsubsection{Reliability Analysis}

The reliability test is performed firstly for the items within theory of planned behavior model and then for the constructs of storytelling. The internal consistence of measures (reliability) is usually investigated by Cronbach's alpha. The higher value of Cronbach's alpha is the higher inter-correlations among measures are proved, it implies the higher reliability of measurements. The result of 0.7 and above implies an acceptable level of internal reliability.

Exploring factor analysis in SPSS using principle component methods with varimax rotation has been performed to identify component factors having greater values than one, and verifying whether the questionnaire items properly mapped the corresponding construct. Additionally, two types of tests were used in this evaluation: Bartlett's sphericity test, which was significant at $p<0.001$, as an indicator that the underlying structure of the data is acceptable. In addition, the Kaiser-Meyer-Olkin (KMO), Measurement KMO is used to test the suitability of the data for factor analysis. Which is recommended to exceed 0.6, is used with the result statistic of reliability.

An exploratory factor analysis for constructs within Theory of planned behavior constructs' involves 19 items, in which 5 items are regarded to entrepreneurial intention; The Cronbach's alpha in the first scenario for the original four items is 0.899 , after deleting the items "EI2" the Cronbach's alpha increased to 0,988 . The scale's Cronbach's alpha coefficient of internal reliability proved to be 0,988 ; hence, the scale seemed to have higher internal reliability.

As far as the second construct is concerned 5 items are regarded to attitude toward the behavior; The Cronbach's alpha in the first scenario for the original four items is 0.885 , after deleting the items "ATB4" the Cronbach's alpha increased to 0,913 . The scale's Cronbach's alpha coefficient of internal reliability proved to be 0,913 ; hence, the scale seemed to have higher internal reliability. As for, the third construct "subjective norms": this construct is measured on a 4-item scale. The Cronbach's alpha for the four items is 0,926 ; the scale seemed to have higher internal reliability. Thus, the last construct of the theory of planned behavior is " perceived behavior control"; this construct is measured on a 6-item scale. The Cronbach's alpha in the first scenario for the six items is 0.911 . The Cronbach's alpha in the second scenario after deleting the item "PBC5" is 0.927.; The Cronbach's alpha in the third scenario for the item "PBC4" is 0.960 . Calculated over all three scenarios the Cronbach's alpha is 0,960 ; hence, the scale seemed to have higher internal reliability.

Therefore the storytelling constructs the result indicates that the Cronbach's Alpha for the 19 items is between the ranges of 0.821 to 0.927 , showing the consistency reliability of the measure used in this study are considerably high. The KMO for the 32 items is between the ranges of 0.733 to 0.916 which exceeded the recommended value of at least 0.6 and Bartlett's test of sphericity was significant at $\mathrm{p}<0.001$.

Table 1. Summary of results of factor analysis: reliability, KMO and Bartlett's test

\begin{tabular}{lllll}
\hline Scales & N of items & Cronbach's alpha & KMO & Bartlett's test \\
\hline $\begin{array}{l}\text { Entrepreneurial intention } \\
\text { Attitude toward the }\end{array}$ & 4 &, 988 &, 794 &, 000 \\
behavior & &, 913 &, 764 &, 000 \\
$\begin{array}{l}\text { Subjective norms } \\
\text { Preceived behavioral }\end{array}$ & 5 & & &, 000 \\
control & 4 &, 926 &, 855 &, 000 \\
Knowledge & 5 &, 960 &, 812 &, 000 \\
Inspiration & 3 &, 821 &, 849 &, 000 \\
Transportation & 8 &, 853 &, 733 &, 000 \\
\hline
\end{tabular}

\subsubsection{Validity Analysis}

After confirming the reliability of the measurement instrument, the next and final step before the testing of the hypotheses is to review validity of the survey. In order, to check the validity of variables, a confirmatory factor analysis was employed for the variables. Confirmatory factor analysis (CFA) was carried out in AMOS 18 (Byrne, 2004) to test the fit of the measurement model, using the Maximum Likelihood estimation procedure and the correlation matrix as input. The validity analysis is conducted in two steps, the convergent validity and then the discriminant validity. 


\subsubsection{Convergent Validity}

As a test of convergent validity, we used a procedure recommended by Larker and Fornell (1981) using the latter, which is based on the calculation of the average variance extracted (AVE). Average variance extracted (AVE) measures the fraction of the construct variance explained by its indicators, and it is used as an indicator of convergent validity (Liñán, 2008). A level above 0.5 is usually considered acceptable. The results of this analysis are presented in Table 4. The Average Variance Extracted (AVE) is presented. The AVE of all the variables is over 0.5 (ranging from 0.606 to 0.953 ), so validity is confirmed. Although the AVE of knowledge is 0.481 . The result of the confirmatory factor analysis demonstrates that the majority of constructs fitted the data appropriately. The estimated parameters were statistically significant between the latent and measured variables. Thus, the results proved convergent validity in this study.

Table 2. Results of convergent analysis: average variance extracted

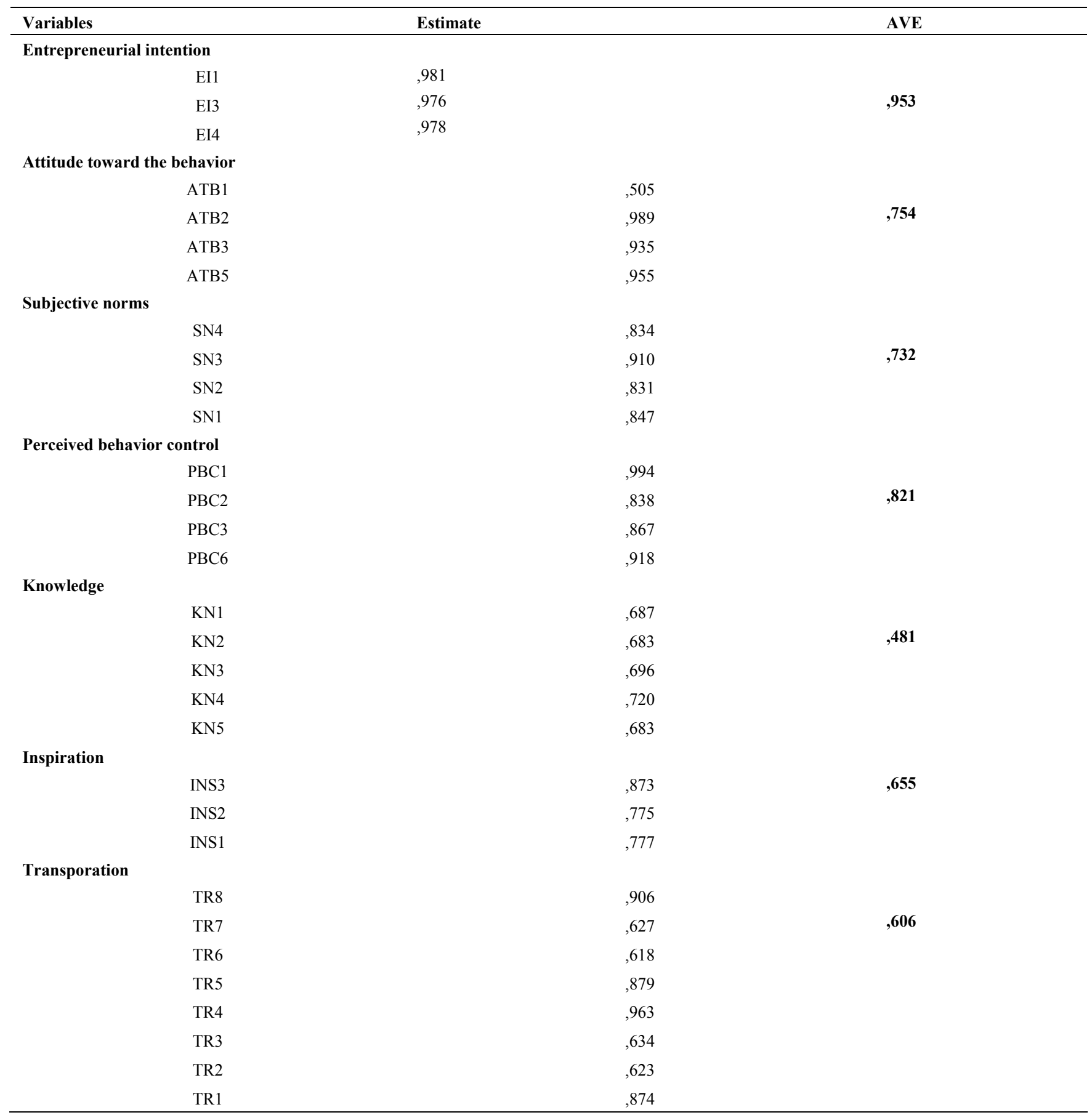




\subsubsection{Discriminant Validity}

Discriminant validity is a second important condition for validity. It was checked to ensure observed variables were measuring only one factor, and thus were not highly correlated with other latent variables ( Micheels and Gow, 2008). As a test of discriminant validity, we have used a procedure recommended by Bagozzi et al. (1991) and Li et al (1998). Within each subset of measures, pairs of constructs were assessed in a series of two-factor confirmatory models. Then, we ran each model twice, once constraining the correlation between the two constructs to unity and once freeing the parameter. the measurement model was compared with a model that constrained the correlations among the constructs to unity and examined the change in chi-square $(\chi 2)$.The results in Table 3 indicate that the chi-square values were significantly lower for the unconstrained models, it may be said that the discriminant validity of those constructs is adequate.

Table 3. Results of discriminant analysis

\begin{tabular}{|c|c|c|c|}
\hline Constructs & $\chi^{2}$ & df & $\Delta \chi^{2}$ \\
\hline \multicolumn{4}{|c|}{ Attitude toward the behavior vs subjective norms } \\
\hline Unconstrained & 67,7 & 19 & \multirow[t]{2}{*}{11,7} \\
\hline Constrained & 79,4 & 20 & \\
\hline \multicolumn{4}{|c|}{ Attitude toward the behavior vs perceived behavior control } \\
\hline Unconstrained & 126,6 & 19 & \multirow[t]{2}{*}{14,1} \\
\hline Constrained & 140,7 & 20 & \\
\hline \multicolumn{4}{|c|}{ Subjective norms vs perceived behavior control } \\
\hline Unconstrained & 59,5 & 19 & \multirow[t]{2}{*}{3,1} \\
\hline Constrained & 62,6 & 20 & \\
\hline \multicolumn{4}{|c|}{ Knowledge vs inspiration } \\
\hline Unconstrained & 21,3 & 19 & \multirow[t]{2}{*}{0,8} \\
\hline Constrained & 22,1 & 20 & \\
\hline \multicolumn{4}{|c|}{ Knowledge vs transportation } \\
\hline Unconstrained & 365,9 & 64 & \multirow[t]{2}{*}{1,7} \\
\hline Constrained & 367,6 & 65 & \\
\hline \multicolumn{4}{|c|}{ Inspiration vs transportation } \\
\hline Unconstrained & 252,5 & 43 & \multirow[t]{2}{*}{4,3} \\
\hline Constrained & 256,8 & 44 & \\
\hline
\end{tabular}

Note. The $\left(\Delta \chi^{2}\right)$ were all significant $(\mathrm{p}<0.001)$.

\subsection{Model Fit and Testing Hypotheses}

\subsubsection{Model Fit}

Confirmatory factor analysis (CFA) was used out in AMOS 18 (Byrne, 2009) to test the fit of the measurement model, using the Maximum Likelihood estimation procedure and the correlation matrix as input. The Overall model fit is assessed by the number of indexes. Chi-square $\left(\chi^{2}\right)$ is traditional test for discrepancy between sample covariance matrix and population covariance matrix. According to Byrne (2001), this criterion has been recognized to be sensitive with sample size so that it should be used as quickly overview of model fit. Amos 18 can report a number of alternative indexes of fit: Root mean square residual (RMR); goodness-of-fit index (GFI), normed fit index (NFI), comparative fit index (CFI),Tucker-Lewis index (TLI), Incremental Fit Index (IFI), root mean square error of approximation (RMSEA). Acceptable model fit are indicate by RMR and RMSEA values below 0.08, and GFI, NFI, TLI, IFI and CFI value exceeding 0.90 (Byrne, 2001). This study will use the value of Chi-square, RMSEA, GFI, IFI and CFI as criterion to examine the Goodness of Fit of the models.

The model appeared fitting badly the present data, chi-square for the model is 2540 with 422 degree of freedom $(\mathrm{p}<0.0001)$; RMSEA value is 0,142 within the recommended level, and CFI, GFI and IFI are ranging from 0.64 to 0.783 less than the recommended level of 0.9 . The results of standardized regression coefficient from the estimation are presented in table 4. 
Table 4. Index of the fit of the model

\begin{tabular}{llllllll}
\hline Index of fit & Chi-Square & DF & P & GFI & IFI & CFI & RMSEA \\
\hline Value & 2540 & 422 &, 000 &, 640 &, 783 &, 782 &, 142 \\
\hline
\end{tabular}

Given that the model has not proven to have bad fit indices, we proceed to examine the modification indices in order to ameliorate the model fit results (Byrne, 2004). The model examination suggested that several error terms were correlated. As suggested by Jöreskog \& Sörbom (1996), the options for dealing with correlated error terms are to either co-vary them or to drop one or both of the items, the model respecification undertaken for our model was based on the first option.

The Goodness of fit of modified model is as good as presented in table 5. The modified model fit better the data than initial model by all indexes, chi-square (1322, 4 ; $\mathrm{df}=416 ; \mathrm{p}=0.000)$, RMSEA (0.093), and CFI, GFI and IFI are ranging from 0.735 to 0.907 .

Table 5. Index of the fit of the model after modification

\begin{tabular}{llllllll}
\hline Index of fit & Chi-Square & DF & P & GFI & IFI & CFI & RMSEA \\
\hline Value & 1322,4 & 416 &, 000 &, 735 &, 907 &, 907 &, 093 \\
\hline
\end{tabular}

\subsection{Testing of Hypotheses}

Amos 18, a structural equation modeling (SEM) program, was used to test the relationships among the variables. A hypotheses test refers to the determination of whether the hypothesis is rejected or is accepted. This section will discuss the testing of each individual hypothesis. The results of hypotheses tests of the relationship between constructs of the theory of planned behavior and constructs of storytelling are given in table 10 . To accept any hypothesis the $\mathrm{p}$ value of the variable must be $<0.05$ and the CR value must be $>1,96$.

The conceptual framework consists of two kinds of hypotheses: the hypotheses one through three addresses the levels of entrepreneurial intention and its dimensions, whereas the following hypotheses four through six are related to the relationship between entrepreneurial intention and its dimensions with storytelling's construct.

Regarding the hypothesis related to the theory of planned behavior, table 8 shows that, all attitude toward the behavior, subjective norms and perceived behavior control are significantly and positively related to entrepreneurial intention $(\mathrm{p}<0.05)$ and the $\mathrm{CR}$ value were successively $(\mathrm{CR}=5,202 ; \mathrm{CR}=4,675 ; \mathrm{CR}=2,592)$. We therefore accept hypotheses $\mathrm{H} 1$ and $\mathrm{H} 2$ and $\mathrm{H} 3$.

As for the next step, it will be conducted to test the relationships between storytelling's construct and entrepreneurial intention.

Hypotheses 4 were partially supported, whereby both $\mathrm{H} 4 \mathrm{a}(\mathrm{CR}=3,257, \mathrm{p}=0,001)$ and $\mathrm{H} 4 \mathrm{c}(\mathrm{CR}=3,243, \mathrm{p}=0,001)$ were significantly and positively related to attitude toward the behavior and perceived behavior control but not H4b ( $p=0,750)$ which was not statistically significant. So it will be rejected. Hypothesis 5, on the other hand, was partially supported whereby $\mathrm{H} 5 \mathrm{~b}$ only inspiration was significantly and positively related to subjective norms $(\mathrm{CR}=9,302, \mathrm{p}=0,000)$ but not to attitude toward the behavior $(\mathrm{p}=0,318)$ and perceived behavior control $(\mathrm{p}=0,515)$ which was not statistically significant.

In Hypothesis 6, results show that the impact of transportation from storytelling was not statistically significant on attitude toward the behavior $(\mathrm{p}=0,167)$, on subjective norms $(\mathrm{p}=0,421)$ and on perceived behavior control ( $\mathrm{p}$ $=0,926)$. Hence, Hypotheses 6 were not supported. 
Table 6. Result of regression weights: (group number 1 - default model)

\begin{tabular}{lllllll}
\hline & & & Estimate & S.E. & C.R. & P \\
\hline Subjective norms & $<---$ & Inspiration & 1,078 &, 116 & 9,302 & $* * *$ \\
Subjective norms & $<---$ & Knowledge &, 045 &, 140 &, 319 &, 750 \\
Subjective norms & $<---$ & Transportation &,- 046 &, 057 &,- 805 &, 421 \\
Attitude toward the beavior & $<---$ & Knowledge &, 551 &, 169 & 3,257 &, 001 \\
Perceived behavior control & $<---$ & Knowledge &, 895 &, 276 & 3,243 &, 001 \\
Attitude toward the behavior & $<---$ & Inspiration &,- 112 &, 112 &,- 998 &, 318 \\
Perceived behavior control & $<---$ & Inspiration &, 126 &, 193 &, 651 &, 515 \\
Perceived behavior control & $<---$ & Transportation &, 010 &, 107 &, 093 &, 926 \\
Attitude toward the behavior & $<---$ & Transportation &, 083 &, 060 & 1,382 &, 167 \\
Entrepreneurial intention & $<---$ & Attitude toward the behavior &, 658 &, 126 & 5,202 & $* * *$ \\
Entrepreneurial intention & $<---$ & Subjective norms &, 328 &, 070 & 4,675 & $* * *$ \\
Entrepreneurial intention & $<---$ & perceived behavior control &, 157 &, 061 & 2,592 &, 010 \\
\hline
\end{tabular}

\section{Conclusion}

The fundamental objective of our research is to examine whether and how storytelling could influence intentions of new venture creation by articulating and empirically testing a theoretical model that specified the mechanisms by which this influence could be exerted, in order to determine the effect of storytelling on entrepreneurial intention.

Our research attempt is to compile numerous researchers that have tried to examine the concept of entrepreneurial intention (Ajzen 1991; Krueger, Reilly \& Carsrud, 2000; Krueger \& Carsrud, 1993; Davidsson 1995) and the concept of storytelling (Denning, 2005; Simmons, 2001; Shankar, et al, 2001; Boje, 1991; Snowden, 1999). We try to study these concepts and factors in the Tunisian context. We focus on the definition, the causes and determinant of both entrepreneurial intention and storytelling and we focus particularly on whether and how storytelling could influence entrepreneurial intention.

Our research includes both entrepreneurial intention that has a potential effect on entrepreneurship and the storytelling that has a potential effect on social science. But the impact of these mentioned factors differ from one situation to another. It will be crucial to make a similar research, but in large samples that include students from different disciplines, different regions and different conditions.

This research can test our theoretical model and extend them if necessary by other factors. In this context, we can study the impact of the same factors on other forms of entrepreneurship context like mentoring.

\section{Discussion, Limitations and Implications}

Using the conceptual model of Ajzen (1991) theory of planned behavior, the aim of this study was to examine the influence of storytelling's construct (knowledge, inspiration and transportation) directly on attitude toward the behavior, subjective norms and perceived behavior control of intention to start a business. The applicability of the theory of planned behavior to entrepreneurship had received extensive empirical support in the past (Liñán and Chen, 2006). Overall, our findings are consistent with other studies which show that the attitude towards the behavior, subjective norms and perceived behavior control have a positive influence on entrepreneurial intention. In fact, the finding of our study confirms that attitude toward the behavior, subjective norms and perceived behavior control are an important predictor and determinant of entrepreneurial intention of Tunisian engineering student. Indeed, attitude toward the behavior, subjective norms and perceived behavior are significantly and positively related to entrepreneurial intention $(\mathrm{p}<0.05)$.

These results indicate that Tunisian engineering students have the ability and the desire to become entrepreneurs. Additionally, it also implies that the entrepreneurial culture seems to be up to date in Tunisia. Moreover, the results can be explained by the increasing of the unemployment rate in Tunisia especially after the revolution which might appear Entrepreneurship as a potentially attractive job opportunity. Moreover, this study has been 
used Ajzen's model (1991) as a starting point. It helps to explain the factors influencing the intention to start a firm. However, storytelling's constructs has been incorporated as a novel factor to this model.

Knowledge from storytelling has been found to have a positive effect on attitude toward the behavior and perceived behavior control. These results indicate storytelling could be a key point of stimulating entrepreneurial intentions. Furthermore, results indicate that storytelling can play a crucial role to motivate engineering student to be self employments. This is explained by the way that stories allow subjective and the individualized and objective knowledge. In fact through listening to the narratives of entrepreneurs, we can begin to grasp the enormity of entrepreneurship that has so far defied complete explanation or definition. In turn, this may increase important issues for the practice of stimulating entrepreneurial intentions. On the other hand knowledge was found to have no significant effect on subjective norms.

As for the inspiration from storytelling, we have found that inspiration has a positive effect on subjective norms, the positive effect of the inspiration indicates the existence of a trigger, encouraging students to pursue a career as an entrepreneur. It confirms that storytelling can be a source of positive triggers. The effect between inspiration and both attitude toward the behavior and subjective norms were not statistically significant.

Besides transportation from storytelling, the results indicate that the effect on subjective norms was not statistically significant. In fact, as shown by Cohen (2001), becoming transported into a story is often, but not always, associated with identifying with a main character. Regarding the effect on both attitude toward the behavior and perceived behavior control, it were also not statistically significant.

The results of our empirical research deal with the idea that storytelling can act as a trigger and informational tool in the field of entrepreneurship, suggesting also that story may be the point of departure for new business creation. These results given by our empirical research concerning the impact of storytelling's elements on entrepreneurial intention, present to us a new avenue of research in the context of entrepreneurship. In so doing, it examines empirically how engineering students actually react to entrepreneurial stories, rather than inferring their reactions from entrepreneurial decision. This Avenue is manifested in the study of the type of different reaction to entrepreneurial stories and its effect on intention to be self employment. However, as in all research, our research nominates a few numbers of limitations that should be raised in future research. Several of them may be mentioned:

The first limitation derives from the characteristics of the sample selected. Future studies should be done on a given sample from the general adult population (Liñán, 2008). More information on students in different discipline would help us to establish a greater degree of accuracy on this matter. The second limitation is about giving more importance to the point of personal characteristics of the sample which seems to have a significant influence on the results. In fact as shown by Lüthje, C., \& Franke, N (2003), the conviction to start up a new venture is to some extent a question of personality structure like (self-efficacy, risk-taking, need for achievement, proactiveness, attitude towards entrepreneurship, behavioral control and internal locus of control) .As a consequence, the measures that we propose will not have the same effects on all people. It seems more talented to focus the stimulating story on the right students particularly those with a propensity to high risk taking and an internal locus of control. Thus, storytelling should guaranties the development of personal traits in order to be considered as a significant trigger of entrepreneurial intention. Future research in entrepreneurial intention and narrative might explore these relations further and involved in more detail and with more sophistication the complex interaction of traits and stories in human personality.

Another important practical implication for storytelling concerns the difference between reading a story and listening to a story. The current tendency in storytelling evaluation is to measure effects in students' intentions to set up a business. Other actionable dimensions, like the storytelling character could be also measured. The longitudinal analysis of our questionnaire will perhaps help us to define such interesting variables that begin before the intention to set up a business.

\section{References}

Ajzen, I. (1985). From Intentions to Actions: A Theory of Planned Behavior. Action Control. Springer Berlin Heidelberg: 11-39.

Ajzen, I. (1991). The theory of planned behavior. Organizational Behavior and Human Decision Processes, 50(2), 179-211. http://dx.doi.org/10.1016/0749-5978(91)90020-T

Barker, R. T., \& Gower, K. (2010). Strategic Application of Storytelling in Organizations: Toward Effective Communication in a Diverse World. Journal of Business Communication, 47(3), 295-312. http://dx.doi.org/10.1177/0021943610369782 
Baron, J. B. (1992). Intention, Interpretation, and Stories. Duke Law Journal, 42(3), 630-678. http://dx.doi.org/10.2307/1372841

Brown, L. M. (1997). Storytelling: a cultural studies approach. Simon Fraser University.

Byrne, B. M. (2004). Testing for Multigroup Invariance Using AMOS Graphics: A Road Less Traveled. Structural Equation Modeling: A Multidisciplinary Journal, 11(2), 272-300. http://dx.doi.org/10.1207/s15328007sem1102_8

Carter, K. (1993). The Place of Story in the Study of Teaching and Teacher Education. Educational Researcher 22(1), 5-18. http://dx.doi.org/10.3102/0013189X022001005

Chanmongkolpanich, K., \& Panthong, S. (2009). The Internationalization Process of Telenor: A Case Study of Telenor in Thailand, KTH.

Cheng, C. W. (2007). The Effects of English Storytelling on Learning Attitudes and English Proficiency of the Sixth-Grade Students.

Davidsson, P. (1995). Determinants Of Entrepreneurial Intentions. RENT XI Workshop. Piacenza, Italy.

Fayolle et al. (2006). Effect and Counter-effect of Entrepreneurship Education and Social Context on Student's Intentions/Efectos de la formación y el contexto social sobre las intenciones empresariales de los estudiantes. Estudios de Economía Aplicada, 24, 509-523.

Fornell, C., \& Larcker, D. F. (1981). Evaluating structural equation models with unobservable variables and measurement error. Journal of Marketing Research, 39-50. http://dx.doi.org/10.2307/3151312

Franke, N., \& Lüthje, C. (2004). Entrepreneurial intentions of business students-A benchmarking study. International Journal of Innovation and Technology Management, 1(3), 269-288. http://dx.doi.org/10.1142/S0219877004000209

Green, M. C., \& Brock, T. C. (2000). The role of transportation in the persuasiveness of public narratives. Journal of Personality and Social Psychology, 79(5), 721. http://dx.doi.org/10.1037/0022-3514.79.5.701

Green, M. C., \& Carpenter, J. M. A. (2011). Transporting into narrative worlds: New directions for the scientific study of literature. Scientific Study of Literature, 1(1), 113-122. http://dx.doi.org/10.1075/ssol.1.1.12gre

Guerrero et al. (2008). The impact of desirability and feasibility on entrepreneurial intentions: A structural equation model. International Entrepreneurship and Management Journal, 4(1), 35-50. http://dx.doi.org/10.1007/s11365-006-0032-x

Heo, H. (2004). Story telling and retelling as narrative inquiry in cyber learning environments.

Johansson, A. W. (2004). Narrating the Entrepreneur. International Small Business Journal, 22(3), 273-293. http://dx.doi.org/10.1177/0266242604042379

Kaye, M. (1995). Organisational myths and storytelling as communication management: A conceptual framework for learning an organisation's culture. Journal of Management \& Organization, 1(2), 1-13. http://dx.doi.org/10.5172/jmo.1995.1.2.1

Krueger et al. (2000). Competing models of entrepreneurial intentions. Journal of Business Venturing, 15(5-6), 411-432. http://dx.doi.org/10.1016/S0883-9026(98)00033-0

Krueger, N. F. (1993). The impact of prior entrepreneurial exposure on perceptions of new venture feasibility and desirability. Entrepreneurship Theory and Practice, 5-21.

Krueger, N. F., \& Carsrud, A. L. (1993). Entrepreneurial intentions: Applying the theory of planned behaviour. Entrepreneurship \& Regional Development, 5(4), 315-330. http://dx.doi.org/10.1080/08985629300000020

Krueger, N. F., \& Brazeal, D. V. (1994). Entrepreneurial potential and potential entrepreneurs. Entrepreneurship Theory and Practice, 18, 91-91.

Larty, J., \& Hamilton, E. (2011). Structural approaches to narrative analysis in entrepreneurship research: Exemplars from two researchers. International Small Business Journal, 29(3), 220-237. http://dx.doi.org/10.1080/08985629300000020

Laviolette et al. (2012). The impact of story bound entrepreneurial role models on self-efficacy and entrepreneurial intention. International Journal of Entrepreneurial Behaviour \& Research, 18(6), 720-742. http://dx.doi.org/10.1108/13552551211268148 
Li et al. (1999). The relationships between market-driven learning and new product success in export markets. International Marketing Review, (16), 476-503. http://dx.doi.org/10.1108/02651339910300459

Linan et al. (2011). Regional variations in entrepreneurial cognitions: Start-up intentions of university students in Spain. Entrepreneurship and Regional Development, 23(3-4), 187-215. http://dx.doi.org/10.1080/08985620903233929

Liñán, F. (2008). Skill and value perceptions: how do they affect entrepreneurial intentions? International Entrepreneurship and Management Journal, 4(3), 257-272. http://dx.doi.org/10.1007/s11365-008-0093-0

Liñán, F., \& Chen, Y. W. (2006). Testing the entrepreneurial intention model on a two-country sample.

Lorz et al. (2011). The Impact of entrepreneurship education on entrepreneurial intention. Ph. D. Dissertation, The University of St. Gallen.

Lounsbury, M., \& Glynn, M. A. (2001). Cultural entrepreneurship: stories, legitimacy, and the acquisition of resources. Strategic Management Journal, (22), 545-564. http://dx.doi.org/10.1002/smj.188

Lüthje, C., \& Franke, N. (2003). The 'making'of an entrepreneur: testing a model of entrepreneurial intent among engineering students at MIT. $R \& D$ Management, 33(2), 135-147. http://dx.doi.org/10.1111/1467-9310.00288

Micheels, E. T., \& Gow, H. R. (2008). Market orientation, innovation and entrepreneurship: an empirical examination of the Illinois beef industry. International Food and Agribusiness Management Review, 11(3), $31-56$.

Mitchell, H. (2005). Knowledge sharing-The value of story telling. International Journal of Organisational Behaviour, 9(5), 632-641.

Ramazan, U., \& Murat, K. (2013). The Emergence of Entrepreneurial Intentions in Indigenous Entrepreneurs: The Role of Personal Background on the Antecedents of Intentions. International Journal of Business and Management, 8(5).

Richard, P., \& Bagozzi, Y. Y. (1991). Assessing Construct Validity in Organizational Research. Administrative Science Quarterly, 36(3), 421-458. http://dx.doi.org/10.2307/2393203

Robinson et al. (1991). An attitude approach in the prediction of entrepreneurship. Entrepreneurship Theory and Practice, 13-31.

Snowden, D. (1999). Story telling: an old skill in a new context. Business Information Review, 16(1), 30-37. http://dx.doi.org/10.1177/0266382994237045

Thrash et al. (2010). Inspiration and the promotion of well-being: Tests of causality and mediation. Journal of Personality and Social Psychology, 98(3), 488-506.

Thrash, T. M., \& Elliot, A. J. (2003). Inspiration as a psychological construct. Journal of Personality and Social Psychology, 84(4), 871-889. http://dx.doi.org/10.1037/0022-3514.84.4.871

Thrash, T., \& Elliot, A. (2004). Inspiration: Core Characteristics, Component Processes, Antecedents, and Function. Journal of Personality and Social Psychology, 87(6), 957-959. http://dx.doi.org/10.1037/0022-3514.87.6.957

Villanueva, J. (2012). Does it matter how you tell it? On how Entrepreneurial Storytelling Affects the Opportunity Evaluations of Early-Stage investors, University of Minnesota.

Zampetakis, L., \& Moustakis, V. (2006). Linking creativity with entrepreneurial intentions: A structural approach. The International Entrepreneurship and Management Journal, 2(3), 413-428. http://dx.doi.org/10.1007/s11365-006-0006-z

\section{Notes}

Note 1. Cited by Krueger \& Carsrud, 1993.

Note 2. Cited by Johansson, 2004s.

Note 3. Cited by V. Souitaris et al, 2007. 


\section{Annexes}

\section{Annexe 1}

\section{Questionnaire}

\section{Part 1:}

Please read this story carefully and then answer the questions as completely as possible. Your thoughtful answers to these questions will help us understand in greater depth your ideas and feelings about the effect of storytelling on entrepreneurial intentions

Sana Fathallah Ghenima was born in Tunisia and graduated university with a degree in industrial engineering, after which she worked for several years in the field of computer science, with experience in heavy industry, simulators, industrial automatization, and IT optimization processes. But in 1999, after taking part in the Summit for World Information Society, Ghenima had an insight that turned her professional life upside down: "I realized that if all the knowledge we have could not be put to work to raise human skills and bring added value to human knowledge and human performance, then that knowledge is meaningless." That insight led her to use those new technologies and the multimedia resources that she knew so well to educate the new generation. For Ghenima, her (and my) generation is "lost" to the educational potential that the digital world can offer, but the younger generations are clued in to information technology from infancy. It's like these kids have microchips on their blood (or mind, I don't know for sure where). They are what some people are calling the "digital native" generation. (The other day a two-year-old girl was trying to change the TV channel by swiping her finger on the screen...).So, seven and a half years ago, Sana Ghenima started Sanabil Med in Tunisia, an exclusively digital publishing house, focused on education. The transition from engineering to publisher - and educator, in a way — was not that hard, since she understood the power of the new tools that technology offered. "It looks easier than what I used to do but it is not, and it is really amazing," Ghenima says. For her, publishing has real targets that she aims for in her work, although it is very difficult—or perhaps impossible — to measure progress. As she puts it, when you are working on an industrial project, you can measure and control the process, but when you are educating people you can't have much control. Nevertheless, "it brings a feeling of worth and the sense that you are doing well for others. It is a very important thing. It is fantastic when you can contribute to create a better society, allowing technology to work for them, and to produce a better community." Today, Sanabil Med (www.sana-bilmed.com) has thirty employees and has already produced seventy titles. Asked about being a successful woman entrepreneur in a world where men usually make the rules, Ghenima said that is was a matter of positioning herself in front of the client. According to Sana, in the first five minutes of conversation, "you must show your knowledge about the issue you are about to discuss." And she adds, "when you stand up for your beliefs, the other person understands what you do and what you know, and they don't look to you as a woman or a man, but as a business person with whom he or she is going to do business."Sana Ghenima offers one last piece of advice for those publishers who are thinking about expanding into digital books: even though you will make some initial mistakes, the important thing is to embrace the new technology, and not avoid it: "We can't avoid bad experiences, but don't not do it!

\section{Part 2:}

\section{Q1- entrepreneurial intention}

\section{a. I have a very low intention of ever starting a business}

b. I prefer to be an entrepreneur rather than to be an employee in a company

c. I am ready to do anything to be an entrepreneur

d. I'll put every effort to start and run my own business
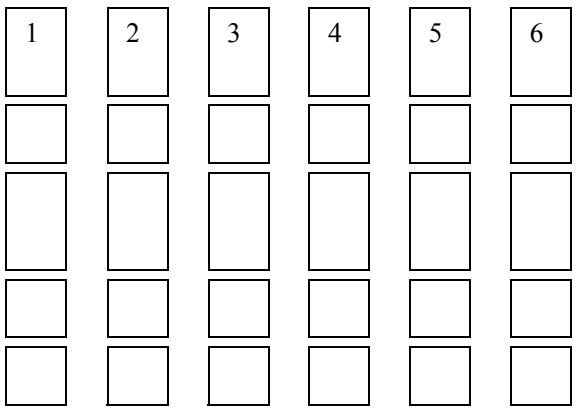

7

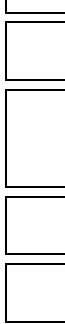

\section{Q2- attitude toward the behavior}

a. Being an entrepreneur implies more advantages than disadvantages to me

b. A career as entrepreneur is attractive for me

c. If I had the opportunity and resources, I would like to start a business

d. Being an entrepreneur would entail great satisfactions for me

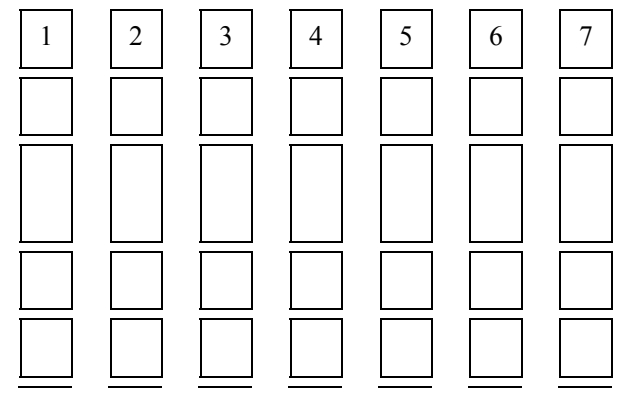




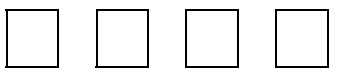

\section{Q3- subjective norms}

\begin{tabular}{|l|}
\hline a. Your close family \\
\hline b. Your close friends \\
\hline c. Your close friends from university \\
\hline d. Other people who are important to you \\
\hline
\end{tabular}

\section{Q4- perceived behavioral control}

a. To start a firm and keep it working would be easy for me

b. I am prepared to start a viable firm

c. I can control the creation process of a new firm

d. I know the necessary practical details to start a firm

e. I know how to develop an entrepreneurial project

f. If I tried to start a firm, I would have a high probability of succeeding

\section{Part 3:}

\section{Q5- knowledge}

a. The story increase your understanding of the attitudes, values and motivation of entrepreneurs (i.e. why do entrepreneurs act?)

b. The story increases your understanding of the actions someone has to take in order to start a business (i.e. what needs to be done?)

c. The story enhances your practical management skills in order to start a business (i.e. how do I start the venture?)

d. The story enhances your ability to develop networks (i.e. who do I need to know?)

e. The story enhances your ability to identify an opportunity (i.e. when do I need to act?
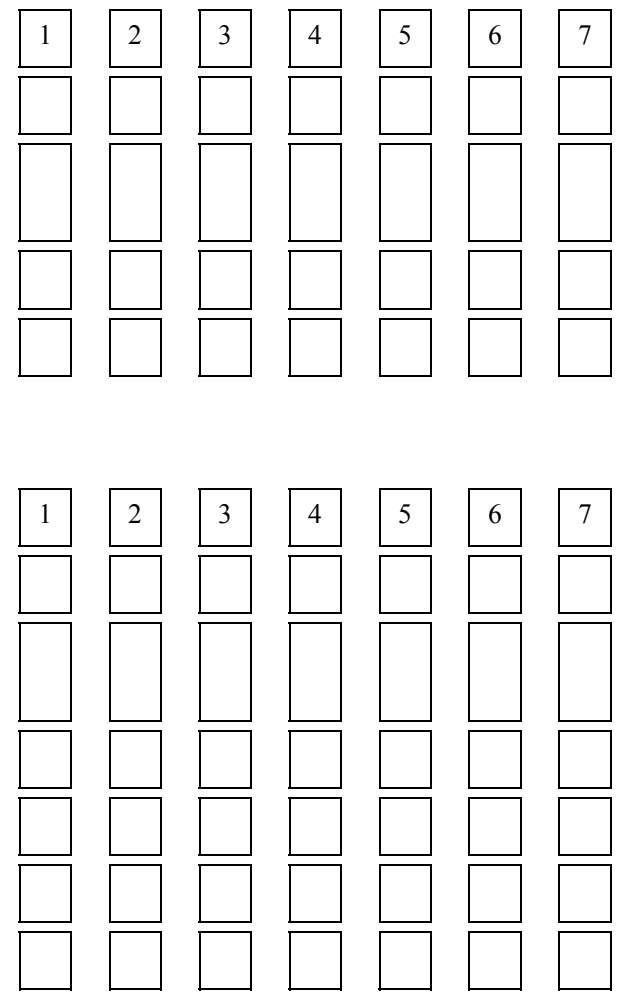

Q6- Inspiration

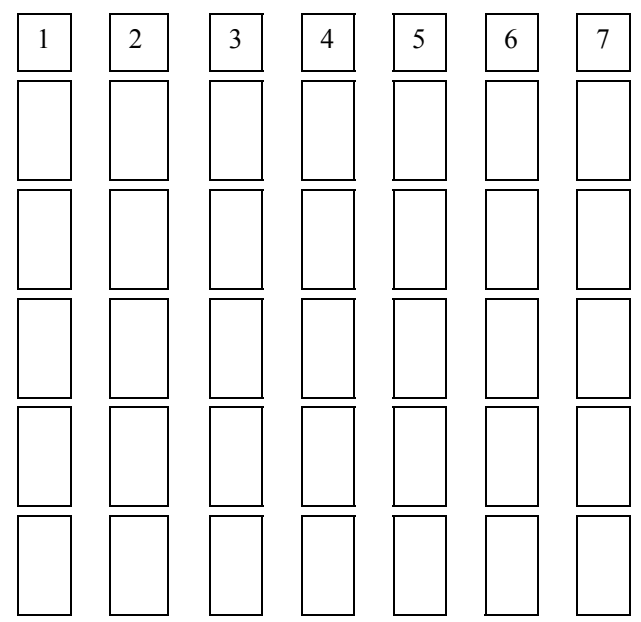

a. Sana Fathallah inspires me to pursue an entrepreneurial career

b. This story energized and motivated me

c. I am inspired to create my own venture 


\section{Q7 - transportation}

a. While I was reading the entrepreneurial stories, I could easily picture the entrepreneurial events in it taking place

b. I could picture myself in the scene of the events described in the entrepreneurial narrative

c. I was mentally involved in the entrepreneurial narrative while reading it

d. After finishing the entrepreneurial narrative, I found it easy to put it out of my mind

e. The entrepreneurial story affected me emotionally

f. I found myself thinking of ways the entrepreneurial story could have turned out differently

g. I found my mind wandering while reading the entrepreneurial story

$\mathrm{h}$.While reading the narrative I had a vivid image of Sana Fathallah

\section{Annexe 2}
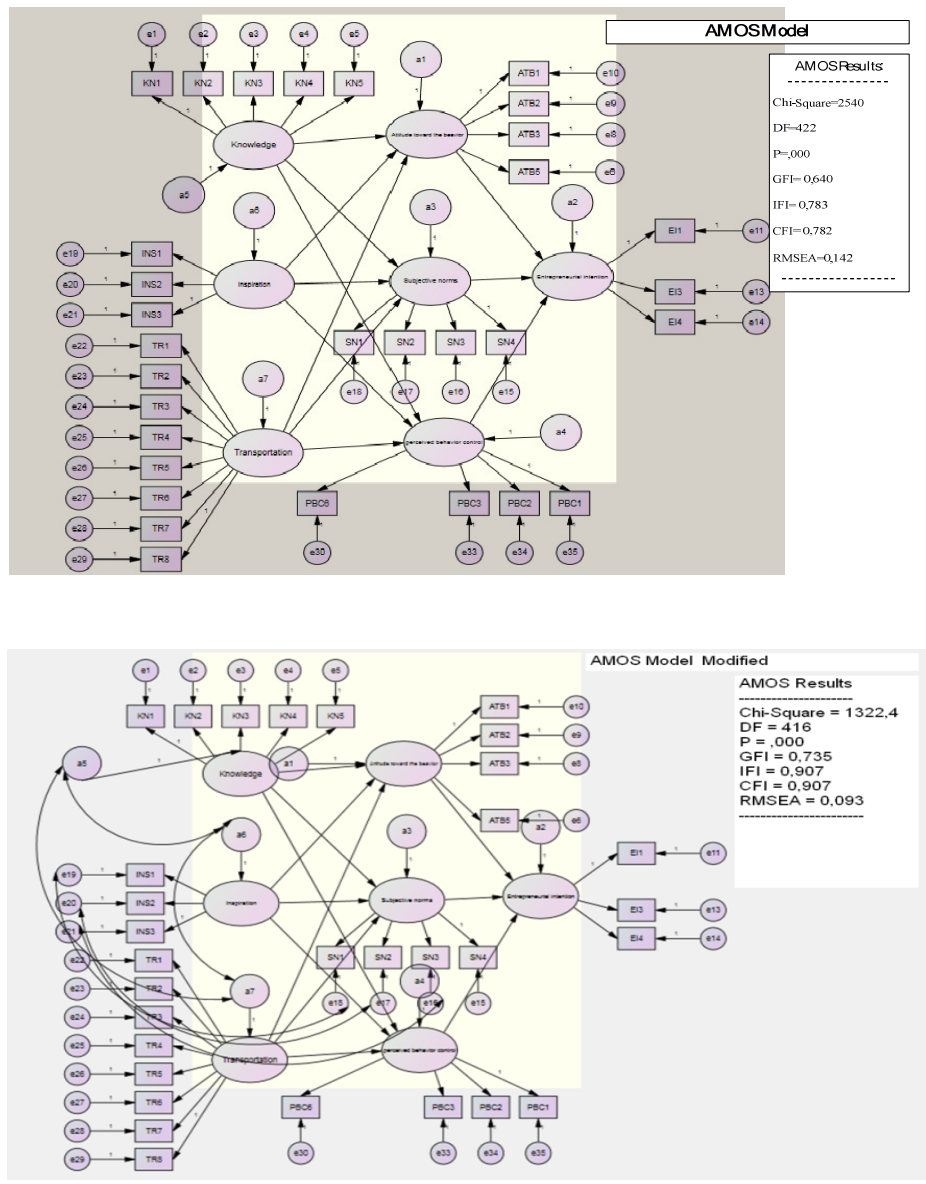


\section{Copyrights}

Copyright for this article is retained by the author(s), with first publication rights granted to the journal.

This is an open-access article distributed under the terms and conditions of the Creative Commons Attribution license (http://creativecommons.org/licenses/by/3.0/). 